\title{
Aktivierung der Apoptose
}

Ein neuer Wirkstoff gegen Brustkrebs zeigt in Laboruntersuchungen bessere Verträglichkeit als vergleichbare Substanzen - und könnte möglicherweise die Wirksamkeit etablierter Krebsmedikamente erhöhen. Eine Arbeitsgruppe der Karl Landsteiner Privatuniversität Krems (KL Krems), der Universität Heidelberg, der Harvard Medical School und weiterer renommierter Gruppen aus den USA und China forscht gemeinsam an dieser Entwicklung.

Die Wirkung der neuen Substanz EU- 5346 beruht auf der Aktivierung der Apoptose, die bei vielen Tumorzellen ausgeschaltet ist und deshalb deren ungehinderte Vermehrung ermöglicht. Sie hemmt die Bindung der beiden Proteine $\mathrm{Mcl}-1$ und Bim in Krebszellen, eine Bindung, die den Mechanismus des programmierten Zelltods aufhebt. Die Wiederherstellung der natürlichen Apoptose verringert so die Lebensdauer von Brustkrebszellen und/oder verhindert die Entstehung von Resistenzen gegen bestimmte Krebsmedikamente. Der Arbeitsgruppe um Dr. Klaus Podar von der KL Krems gelang es, die therapeutische Eignung der Substanz in Kombination mit etablierten Krebsmitteln durch Nachweis der guten Verträglichkeit und hohen Effizienz zu belegen.

Die aktuellen Ergebnisse knüpfen an frühere Forschungen an, in denen es gelang, eine neue, in Tumorzellen gehäuft auftretende Struktur, zu identifizieren, die nun das Ziel der neu entwickelten Substanz zur möglichen

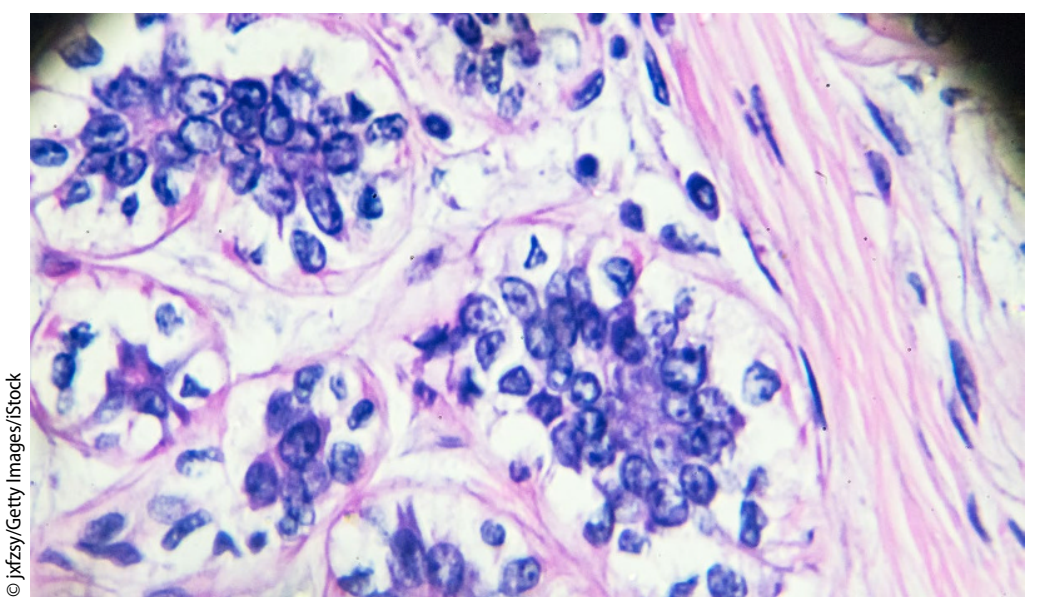

Behandlung von Brustkrebs darstellt. Die jetzt veröffentlichten Daten ebnen den Weg, die Substanz so weiter zu entwickeln, dass sie sich für die klinische Behandlung von Brustkrebs eignet.

\section{Besser verträglich}

Die Entwicklung von Substanzen, die wie EU-5346 durch Hemmung des anti-apoptotischen Proteins $\mathrm{Mcl}-1$ genau diese Effekte erzeugen, steht derzeit im Fokus vieler Forschungsgruppen und der pharmazeutischen Industrie. Doch zeichnen sich viele von ihnen durch starke Nebenwirkungen aus, die eine klinische Anwendung ausschließen. Die Untersuchung von EU-5346 im Labor auch auf dessen Nebenwirkungen zeigte, dass die Substanz im Vergleich weniger Toxizität für Herz, Blut und Nerven aufwies.

Zusätzlich testete die Gruppe die gegen Brustkrebszellen gerichtete Wirkung von EU-5346 in Kombination mit etablierten Brustkrebstherapeutika.
Quelle: Presseinformation Karl Landsteiner Privatuniversität für Gesundheitswissenschaften
Gegen letztere, insbesondere Tamoxifen, Trastuzumab und Paclitaxel, entwickeln Tumorzellen oftmals Resistenzen. In allen Fällen konnte gezeigt werden, dass die Kombination mit EU-5346 die Anti-Tumor-Wirkung der Brustkrebsmedikamente erhöht bzw. reaktiviert. „Für uns bedeuten diese Ergebnisse, dass EU-5346 ein interessanter Kandidat für die weitere Medikamentenentwicklung in einem klinischen Setting ist", fasst Dr. Sonja Vallet, Dr. Vallet, Klin. Abt. f. Innere Medizin 2, Univ.-Klinikum Krems, die Resultate dieser internationalen Zusammenarbeit zusammen. Es wird angenommen, dass Mcl-1 Hemmer nicht nur bei Brustkrebs, sondern auch bei anderen Tumorarten eine profunde, therapeutische Rolle spielen können. Weitere Forschungsarbeiten zur Analyse der Häufigkeit von $\mathrm{Mcl}-1$ und anderer spezieller anti-apoptotischer Proteine in individuellen Tumorzellen sollen das Potential für die klinische Anwendung klären und Informationen über die mögliche Wirksamkeit von EU-5346 alleine, aber auch über rational abgeleitete Therapiekombinationen für den personalisierten Einsatz schaffen.

Wien klin Mag 2019 · 22:94 https://doi.org/10.1007/s00740019-0282-1 (c) Springer-Verlag GmbH Austria, ein Teil von Springer Nature 2019 